\title{
Laparoscopic Cholecystectomy versus Mini-laparotomy Cholecystectomy: A Randomized Controlled Trial
}

\author{
Wael Barakaat Ahmed, MD; Ahmed Gaber Mahmoud, MD; \\ Kamal A.M. Hassanein, FRCS, Ph.D.
}

General Surgery Department, Sohag faculty of medicine, Sohag University.

Background and aim: Minimally invasive procedures; laparoscopic cholecystectomy $(L C)$ and Mini-Laparotomy cholecystectomy (MC), have largely replaced the traditional cholecystectomy. The aim of our study was to compare short term outcomes of LC versus MC for the treatment of gallstones.

Patients and methods: This is a prospective study that included patients with gallstones who were referred, randomized and enrolled in the study for elective LC or MC at Sohag University hospital, Egypt; between December 2012 and December 2014. Operation, anaesthesia, rescue analgesics and postoperative care were standardized. The patients were assessed for operation time as primary outcome; length of hospital stay, postoperative pain, and surgical conversion and perioperative complications as secondary outcomes. The patient's outcome was recorded up to four weeks postoperative.

Results: Of 220 patients, 110 underwent LC and 110 underwent MC. The mean operative time for MC group was $42.3 \pm 14.7$ which was significantly lower than LC $52.1 \pm 19.5$ (p value 0.018). There was no statistically significant difference in both groups as regard length of hospital stay, post operative pain, and conversion rate or perioperative complications.

Conclusion: MC is an appropriate minimal invasive procedure for cholecystectomy without the financial resources for laparoscopic equipment and rightly trained surgical teams.

Key words: Laparoscopy, minilaparotomy, cholecystectomy; randomized trial.

\section{Introduction:}

Since late 1980s, laparoscopic cholecystectomy (LC) was introduced and became popular worldwide. However, this popularity was related partly to the appealing technology and industry driven motives. ${ }^{1}$

Classic open cholecystectomy has remained as the gold standard for over a century. With time, surgeons have started to get shorter incisions for a proposed quicker recovery. Small-incision or mini-laparotomy cholecystectomy (MC) provides a less invasive approach and it was described by many surgeons. ${ }^{2}$

However due to the cost incurred thereof and surgical training needed, open cholecystectomy is still performed on a very large scale in most parts of the third world countries. ${ }^{3}$
The advantages and disadvantages of minilaparotomy surgery in relation to laparoscopic cholecystectomy are still questionable. Metaanalyses available on Cochrane database and comparing MC and LC show no differences observed in mortality, complications, and postoperative recovery. 4

The aim of this study was to compare the short term results and outcomes of LC with the $\mathrm{MC}$ for treatment of noncomplicated gallstones as regard operative time, post operative pain, conversion rate, length of hospital stay and return to labor activities, and perioperative complications (i.e. Intraoperative and postoperative).

\section{Patients and methods:}

This study was designed as a prospective randomized blinded clinical trial carried 
out in the department of surgery in Sohag University hospitals between December 2012 and December 2014.

\section{Randomization Blind:}

The computer generated randomization was concealed with the sealed envelope method until the patient enrolment. After randomization the envelopes were opened. Altogether 220 consecutive patients with symptomatic noncomplicated gallstone disease were randomized to undergo either MC $(n=110)$ or LC $(n=110)$. All patients, who were scheduled for elective cholecystectomy, were candidates for inclusion in the study.

Patients and methods:

The criteria for scheduling patients were uncomplicated, symptomatic cholecystolithiasis, Age $\geq 18$ years, Body mass index (BMI) more than 18 and less than 35. No significant co morbidities. The American Society of Anesthesiologists (ASA) physical status classification was I or II.

Exclusion criteria were: Acute cholecystitis, a history of pancreatitis, hepatic cirrhosis, suspicion of cancer, previous open upper abdominal surgery, and a suspicion or verified stones in the common bile duct.

Surgical techniques:

All patients had a standardized endotracheal anaesthesia, all operations were performed by the same surgeons, and a standardized technique was used for MC and LC. MC was performed with a 5 to $7 \mathrm{~cm}$ horizontal incision in the right upper abdomen without cutting the muscles. The four trocar technique was used in the LC operations. The postoperative pain management was also standardized. The primary end point evaluated was operative time; the secondary end points were conversion rate, postoperative pain, length of hospital stay and return to labor activity, the incidence of perioperative complications (intraoperative: Gall bladder perforation and common bile duct injuries; and postoperative: Surgical site infection, ileus \& infectious complications). The patients' outcome was recorded up to four weeks after operation.
Ethical committee approval:

Research Ethical Committee approval was obtained for this study. Patients were gave a written consent after receiving verbal and written information.

Statistical analysis: Data were analysed using mean \pm standard deviation (SD) for numerical variables and number (percentage) for non-parametric variables. Statistical Package for Social Sciences (SPSS) version 16 software for statistical analysis was used. Both Student's t-test and Chi-square test were utilized to compare variables. P- Value $<0.05$ was considered statistically significant.

\section{Results:}

During this study period of 220 patients: 110 underwent LC and 110 underwent MC. The baseline patients characteristics Table (1) were insignificant between both group except in LC group. 91 of 110 patients were female and in MC group 75 of 110 were female (p value 0.018 ). The mean patient's age for LC Group was $37.3 \pm 10.9$ and for MC group was $32.6 \pm 10.6$ ( $\mathrm{p}$ value 0.558 ).

The mean operative time in minutes for MC group was $42.3 \pm 14.7$ which was significantly lower than LC $52.1 \pm 19.5$ which was statistically significant ( $p$ value $=0.018$ )

There was 4 cases $(3.63 \%)$ conversion to a conventional open cholecystectomy in the MC-group and 7 cases $(6.36 \%)$ conversion in LC-group, respectively which was not significant $(\mathrm{NS}), \mathrm{P}$ value $=0.861$. The reason for conversion in $\mathrm{MC}$ - group was bleeding $(\mathrm{n}=1)$ and distorted anatomy $(\mathrm{n}=3)$ due to chronic cholecystitis. In LC- group, bleeding $(n=2)$, distorted anatomy $(n=4)$ and one case with suspected CBD injury with negative result after conversion.

There was no statistically significant differences between both groups as regard postoperative pain evaluated by visual analogue score for pain within 24 hours postoperative; where $5.37 \pm 1.63$ and 3.77 \pm 1.66 for $\mathrm{LC}$ and $\mathrm{MC}$ respectively, ( $\mathrm{p}$ value $=0.704$ ).

The perioperative complications were identified in 23 patients $(10.5 \%)$ of all 220 patients; 12 patients of LC and 11 patients of 
Table (1): Patients> baseline and operative data of both cholecystectomy group under study. Data are mean $\pm S D$, number of cases and percent.

\begin{tabular}{|l|l|l|l|}
\hline & \multicolumn{1}{|c|}{ LC n = 110 } & \multicolumn{1}{c|}{ MC n =110 } & P value \\
\hline Age: Mean (year) & $37.3 \pm 10.9$ & $32.6 \pm 10.6$ & 0.558 \\
\hline Sex: & & & \\
Female (n) & 91 & 75 & 0.018 \\
Male (n) & 19 & 35 & \\
\hline Operative time (min) & $52.1 \pm 19.5$ & $42.3 \pm 14.7$ & 0.018 \\
\hline Conversion rate (n) & $7(6,36 \%)$ & $4(3.63 \%)$ & 0.861 \\
\hline Hospital stay (days) & $2.7 \pm 3.9$ & $2.4 \pm 3.9$ & 0.187 \\
\hline Perioperative complication & $16(14.5 \%)$ & $15(13.6 \%)$ & 0.396 \\
\hline
\end{tabular}

Table (2): Intraoperative complications in the two cholecystectomy groups.

\begin{tabular}{|l|l|l|l|l|l|}
\hline Maneuver & None & G.B perforation & Bowel injury & Bleeding & Total \\
\hline LC & 104 & 3 & 1 & 2 & 110 \\
\hline MC & 107 & 2 & 0 & 1 & 110 \\
\hline Total & 211 & 5 & 1 & 3 & 220 \\
\hline
\end{tabular}

$\mathrm{GB}=$ Gall Bladder

Table (3): Post operative complications in the two cholecystectomy groups.

\begin{tabular}{|l|l|l|l|l|l|l|}
\hline Maneuver & None & Bile leak & SSI & Intrabdominal infection & CBD injury & Total \\
\hline LC & 104 & 1 & 3 & 1 & 1 & 110 \\
\hline MC & 102 & 2 & 6 & 0 & 0 & 110 \\
\hline Total & 206 & 3 & 9 & 1 & 1 & 220 \\
\hline
\end{tabular}

$\mathrm{SSI}=$ Surgical site infection, $\mathrm{CBD}=$ Common bile duct

MC respectively, so no statistically significant difference between both group $(\mathrm{P}=0.396)$, Tables (2,3).

Three patients in LC group and six patients in MC group develop superficial wound infection; all were cured by per oral antibiotics. Intra-abdominal infection in the form of right subphrenic collection developed in one case of LC group where CBD injured and no cases in $\mathrm{MC}$ group which treated by aspiration under sonographic guidance.

Bile leaked postoperatively in one case in LC group and in 2 cases in MC group which stopped within 48 hours except the case in LC group, bile leaks persisted in this case where tangential common bile duct injury diagnosed by ERCP and treated by stent in CBD.

The length of hospital stay in the present study for LC $2.7 \pm 3.9$ days and for MC
$2.4 \pm 3.9$ days $(\mathrm{P}=0.187)$ which was not statistically significant. There were no deaths in either group within 30 days of surgery.

\section{Discussion:}

Gallstones are probably as old as mankind. Gallstones were found in an Egyptian mummy ( $21^{\text {st }}$ dynasty, approx. $1000 \mathrm{BC}$ ) and the description of Alexander the Great's final days (323 BC) suggests that he may have died of acute infection of the gallbladder. ${ }^{5}$

When laparoscopic cholecystectomy (LC) was introduced in the late 1980s by Erich Muhe in Boblingen, German, it rapidly became the dominant procedure for gallbladder surgery in the industrialized world. The main reason was that the new method was followed by a smoother postoperative course than conventional cholecystectomy with better cosmetic results. ${ }^{2}$ 
Sub costal oblique incision smaller than 8 cm in length is defined as minilaparotomy. ${ }^{6}$ Can be performed with conventional surgical instruments available in any operating room; is slowly gaining acceptance as a low cost alternative compared to $\mathrm{LC}^{7}$

LC and MC, as minimally invasive procedures have largely replaced the traditional cholecystectomy. However there are discussions about the advantages and disadvantages of minilaparotomy surgery in relation to laparoscopic. ${ }^{4}$

In this randomized trial, we present our experience with 220 patients that were randomized to receive either $\mathrm{LC}$ or $\mathrm{MC}$ for treatment of gall bladder stones.

In this study the mean operative time for MC group was lower than LC ( $p$ value 0.018), which was statistically significant. The systematic review of Purkayastha et al (2007), ${ }^{8}$ showed that the mean of surgical time was 14.1 minutes higher in the group that performed the LC. Other review founded that the mean of operative time was 31.8 minutes higher in the LC. ${ }^{9}$

In our study the rate of conversion was not statistically significant $(P=0.861)$ in both cholecystectomy group and this is comparable to the systematic review done by Castro et al in 2014 showed that Surgical conversion got no statistically significant result ( $\mathrm{p}=0.06$ ); while, the Purkayastha's study (2007), demonstrated statistically significant results for the conversion rate $(\mathrm{p}=0.02)$, where conversion rate in the LCgroup $(9.7 \%)$ was two to three times higher than in the previous studies. ${ }^{8,9}$

Conversion rate is commonly reported as $1.5-10 \%$ depending on the patient population and the associated risk factors. Therefore, surgeons should take chronic inflammation of the gallbladder in account preoperatively while selecting patients to have cholecystectomy regardless of the surgical technique planned to be used. It should be consider that the conversion of an LC or MC will not necessarily lead to a worse outcome.

Castro et al in 2014 showed that the incidence of surgical site infection $(p=0.52)$, perforation of the gallbladder $(\mathrm{p}=0.98)$, injury to $\mathrm{CBD}(\mathrm{P}=1.00)$, postoperative ileus $(\mathrm{p}=0.22)$ and surgical re-intervention $(\mathrm{p}$ $=0.27$ ) were not statistically significant. In this study no statistically significant difference in the peri-operative complications between both group $(\mathrm{P}=0.396)$.

Ros et al. In 2001 reported higher incidence of trauma and complications during the operation in LC group. Keus et al. In 2009 reported 5 cases of surgical complication in LC and 3 cases in MC group.

Postoperative pain in our study show no statistically significant difference between both cholecystectomy group $(\mathrm{P}=0$.704). Shaban Mehrvarz et al. In 2012 reported that Postoperative pain, 24 hours after the surgery, was not statistically significantly different in the two groups. Systematic review and metaanalysis in 2014, showed clearly that the LC showed a lower incidence of postoperative pain $(\mathrm{p}<0.00001) .{ }^{9}$

The length of hospital stay in the present study for LC $2.7 \pm 4$ days and for MC $2.4 \pm 4$ $(\mathrm{P}=0.187)$ was not statistically significant. Purkayastha showed that the mean of hospitalization was 0.8 days higher in the group that performed the MC. Some studies reported similar hospitalizations in both groups of LC and MC. ${ }^{1,15}$ Although McGine et al ${ }^{16}$ stated that hospital stay was shorter in MC group (3.7 versus 4.1 days), however this difference was not statistically significant. According to Majeed et al, ${ }^{17}$ surgeons and clinicians tend to keep patients undergoing MC out of work more than those who underwent LC. However, patients decided their time of sick leave, and those undergoing $\mathrm{MC}$ returned to work at the same time or earlier than those who underwent LC. No mortality occurred in either group. Similar studies did not report any mortality. ${ }^{1}$

\section{Conclusion:}

$\mathrm{MC}$ was comparable to LC; there was no statistically significant difference. However laparoscopy had longer operative time so, we recommend using $\mathrm{MC}$ in our hospitals as an appropriate minimally invasive method for most of the patients without the financial 
resources for laparoscopic equipment and rightly trained surgical teams.

\section{Reference:}

1- Keus F, Gooszen HG, van Laarhoven CJ: Systematic review: Open, small-incision or laparoscopic cholecystectomy for symptomatic cholecystolithiasis. Aliment Pharmacol Ther 2009; 29: 359-378.

2- Tyagi NS, Meredith MC, Lumb JC, Cacdac RG, Vanterpool CC, RaylsKR, Zerega WD, Silbergleit A: A new minimal invasive technique for cholecystectomy: Subxiphoid "minimal stress triangle" microceliotomy. Ann Surg 1994; 220: 617-625.

3- Schmitz R, Rohde V, Treckmann $\mathrm{J}$, et al: Randomized clinical trial of conventional cholecystectomy versus minicholecystectomy. Br J Surg 1997; 84: 1683-1686.

4- Harju J, Aspinen S, Juvonen P, Kokki H, Eskelinen M: Ten-year outcome after minilaparotomy versus laparoscopic cholecystectomy: A prospective randomized trial. Surgical Endoscopy 2013; 1-5.

5- Beal JM: Historical perspectives of gallstone disease. Surg Gyn Obst 1984; 158: 181-189.

6- Sharma AK, Rangan HK, Choubey RP: Minilap cholecystectomy: A viable alternative to laparoscopic cholecystectomy for the Third World? Aust N Z J Surg 1998; 68: 774-777.

7- Seale K, Ledet WP. Mini-cholecystectomy: A safe, cost-effective day surgery procedure. Arch Surg 1999; 134: 308-310.

8- Purkayastha S, Tilney HS, Georgiou P, Athanasiou T, Tekkis PP, Darzi AW. Laparoscopic cholecystectomy versus mini-laparotomy cholecystectomy: A metaanalysis of randomized control trials. Surg Endosc 2007; 21(8): 1294-1300.

9- Castro PM, Akerman D, Munhoz CB, Sacramento Id, Mazzurana M, Alvarez
GA: Laparoscopic cholecystectomy versus minilaparotomy in cholelithiasis: Systematic review and meta-analysis. Arq Bras Cir Dig 2014; 27(2): 148-153.

10- Harju J, Juvonen $P$, Eskelinen $\mathrm{M}$ et al: Minilaparotomy cholecystectomy versus laparoscopic cholecystectomy: Arandomized study, with special reference to obesity. Surg Endosc 2006; 20: 583-586.

11- Harju J, Paakkonen M, Eskelinen M: Minilaparotomy cholecystectomy as a day surgery procedure: Pilot study. Scand J Surg 2007; 96: 206-208.

12- Tang B, Cuschieri A: Conversions during laparoscopic cholecystectomy: Risk factors and effects on patient outcome. J Gastrointest Surg 2006; 10: 1081-1091.

13- Ros A, Gustafsson L, Krook H, Nordgren C, Thorell A, Wallin G, et al: Laparoscopic cholecystectomy versus mini-laparotomy cholecystect omy. Ann Surg 2001; 234: 741-749.

14- Mehrvarz S, Mohebi HA, Motamedi MHK: Laparoscopic cholecystectomy versus small incision cholecystectomy in symptomatic gallstones disease. Journal of the College of Physicians and Surgeons Pakistan 2012; 22(10): 627-631.

15- Secco GB, Cataletti M, Bonfante P, Baldi E, Davini MD, Biasotti B, et al: Laparoscopic versus mini-cholecystectomy: Analysis of hospital costs and social costs in a prospective randomized study. Chir Ital 2002; 54: 685-692.

16- McGine FP, Miles AJG, Uglow M, Ozmen M, Terzi C, Humby M: Randomized trial of laparoscopic cholecystectomy and mini- cholecystectomy. Br J Surg 1995; 82: 1374-1377.

17- Majeed AW, et al: Brown Variations in medical attitudes to postoperative recovery period. BMJ 1995; 311: 296. 


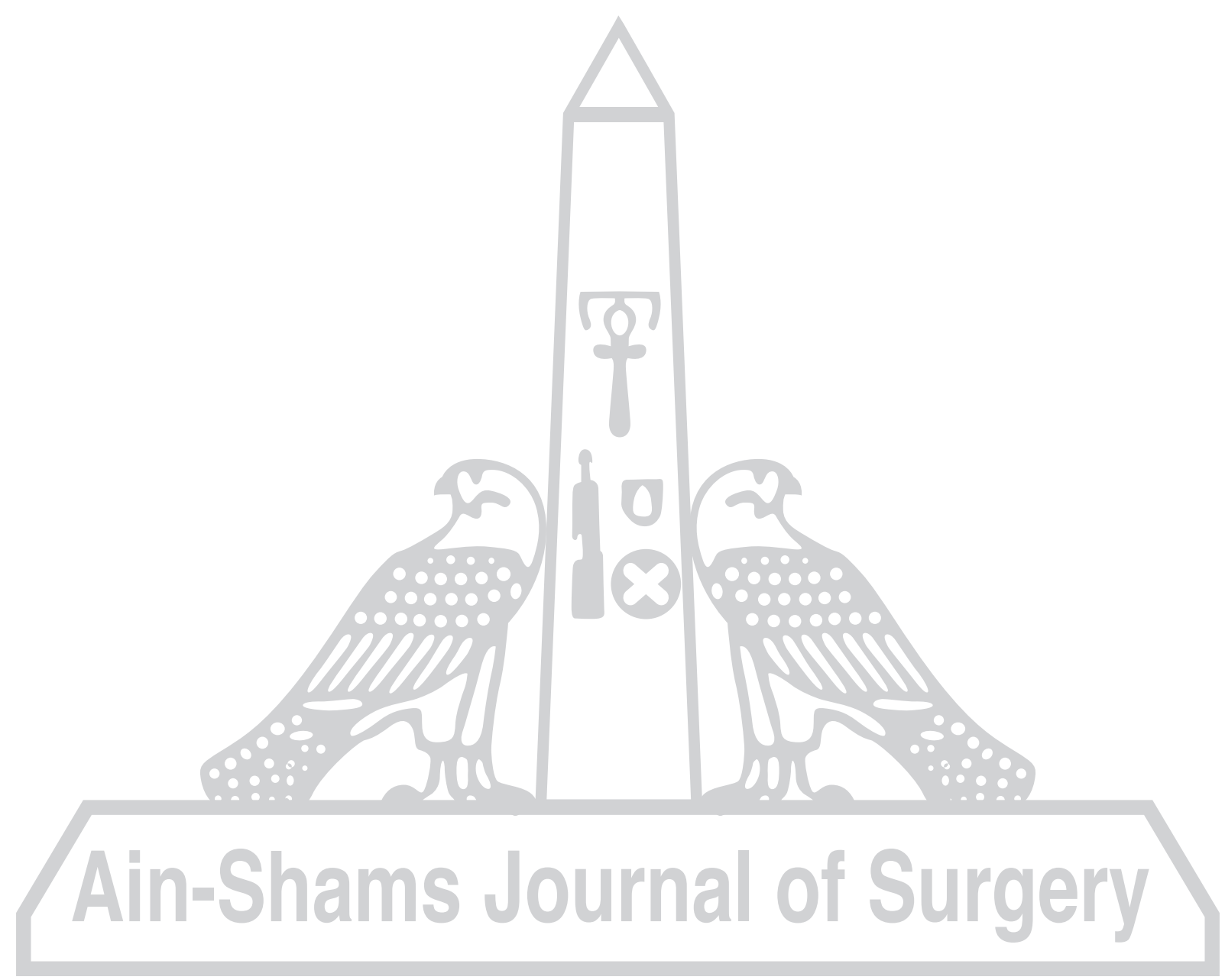

